\title{
A proteção do meio ambiente na Declaração Universal sobre Bioética e Direitos Humanos
}

\section{The environmental protection set on the Universal Declaration about Bioethics and Human Rights}

\author{
José Roque Junges \\ Universidade do Vale do Rio dos Sinos (Unisinos), São Leopoldo, \\ Rio Grande do Sul, Brasil. \\ roquejunges@hotmail.com
}

\begin{abstract}
Resumo: O texto comenta a referência sobre a proteção do meio ambiente no artigo 17 da Declaração Universal sobre Bioética e Direitos Humanos. A análise situa a crise ambiental na tendência à fragmentação do paradigma da modernidade e mostra a necessidade de assumir a ecologia como um paradigma cultural. A perspectiva ecológica da realidade abre o caminho para relacionar saúde e ambiente, permitindo uma visão ecossistêmica da própria saúde humana. Para entender o artigo 17 é necessário levar em consideração as declarações das conferências das Nações Unidas sobre o Meio Ambiente e o Desenvolvimento, principalmente aquela que se realizou no Rio de Janeiro em 1992. Estes documentos partem dos desafios ambientais provocados pelo progresso econômico e sua perspectiva é o desenvolvimento sustentável. A declaração de bioética tem como referência as questões éticas dos avanços das biotecnologias e sua perspectiva são os direitos humanos. O documento acentua a inter-relação dos seres humanos com as outras formas de vida, o uso adequado dos recursos naturais e o papel do ser humano na proteção do meio ambiente, da biosfera e da biodiversidade.
\end{abstract}

Palavras chave: Modernidade. Ecologia. Meio ambiente. Saúde. Bioética.

\begin{abstract}
The text brings comments on the $17^{\text {th }}$ article discoursing about the environmental protection brought by the Universal Declaration about Bioethics and Human Rights. The analysis evaluates the environmental crisis under the fragmentary tendency point of view set by the Modernity Paradigm and shows the need to the ecology to get assumed as a cultural paradigm. The ecological perspective of reality opens the door to connect health with environment, allowing a human health eco-systemic vision. To understand the $17^{\text {th }}$ article is necessary to take into account the declarations emerged from the United Nations Conferences about Environmental and Development, especially that one occurred in 1992, in Rio de Janeiro. These documents have origin in the environmental challenges brought by the economic growth and have its perspective on the sustainable development.
\end{abstract}




\section{Revista Brasileira de Bioética}

The Declaration about Bioethics takes, as a reference, the ethical issues by the biotechnologies advances and its perspective is the human rights. The document emphasizes the inter-relation between human beings and other forms of life, the appropriate use of the natural resources and the human role in the protection of the environment, biosphere and biodiversity.

Key words: Modernity. Ecology. Environment. Health. Bioethics.

Os problemas ecológicos avolumam-se, ameaçando o Sistema Terra. Buracos na camada de ozônio, aumento gradativo da temperatura, desgelamento das calotas polares, mutações climáticas, desertificação de imensas regiões, desaparecimento crescente de espécies vegetais e animais são alguns dos problemas que ameaçam a biosfera.

Cresce em contrapartida a consciência e a sensibilidade ecológica. Florescem Organizações Não-Governamentais (ONG) que lutam pela ecologia. Criam-se fundos para a preservação de ecossistemas e para a proteção de espécies ameaçadas de extinção. Surgem parques de preservação e proteção ambiental. A preocupação ecológica recebe embasamento jurídico por meio de leis em defesa do meio ambiente. Os governos são pressionados a assumir políticas ecológicas que englobem o fator natureza em seus planejamentos. Por isso, a Declaração Universal sobre Bioética e Direitos Humanos da UNESCO não podia deixar de incluir uma clara referência sobre a proteção ao meio ambiente, biosfera e biodiversidade.

Os problemas ecológicos não dependem de uma simples solução técnica, reclamam uma resposta ética. Requerem uma mudança de paradigma na vida pessoal, na convivência social, na produção de bens de consumo e, principalmente, no relacionamento com a natureza. Exigem a necessidade de uma mudança de rota na organização econômico-industrial e político-social da sociedade; de uma conversão das atitudes de consumo e de relacionamento com o ambiente natural e social. Trata-se, no fundo, de uma transformação de mentalidade e de visão do mundo. A preocupação ecológica não traz apenas novos problemas que exigem solução, ela introduz um novo paradigma civilizatório. A ecologia levanta críticas radicais à racionalidade moderna e ao sistema econômico capitalista. Por isso, é necessário abrir um horizonte mais amplo de compreensão crítica das dinâmicas cul- 
turais que movem a sociedade atual para entender a preocupação ecológica da Declaração e tentar situá-la na tradição dos documentos internacionais que falam da proteção do meio ambiente.

\section{O paradigma sociocultural da modernidade}

A modernidade caracteriza-se, antes de tudo, pelo enfraquecimento dos laços comunitários e pelo surgimento do indivíduo. Nas sociedades tradicionais, a identidade do ser humano era dada pela comunidade. Ele não tinha representação fora do seu grupo; os laços comunitários é que o constituíam como sujeito. O enfraquecimento dessa dependência, facilitada pelos poderes que a modernidade foi colocando nas mãos do sujeito, possibilitou a emergência do indivíduo autônomo. O indivíduo moderno caracteriza-se por aquilo que o diferencia dos demais e não por aquilo que o identifica com o seu grupo. $\mathrm{O}$ individualismo, como dinamismo cultural de independência e autonomia, incentivou a busca da originalidade do sujeito e valorizou o ideal da autenticidade de cada um. Cada indivíduo é convidado a ser original e autêntico na sua expressão. Ser indivíduo identifica-se com ser autônomo.

A autonomia é a força propulsora do individualismo cultural. A consciência de ser indivíduo autônomo possibilitou a emergência da consciência dos direitos humanos e da dignidade de cada ser humano. Cada indivíduo é digno em sua originalidade, porque tem a tarefa de se autoconstituir como sujeito pelo exercício da sua existência. Assim, o individualismo cultural moderno está baseado em três categorias fundamentais: a autonomia da consciência, a originalidade singular do indivíduo e a dignidade humana de cada pessoa.

A segunda característica da modernidade é o crescente desencantamento do mundo pelo esvaziamento da natureza de todo animismo e a sua dominação em benefício dos seres humanos, possibilitado pelo surgimento da razão instrumental, matriz da ciência moderna e da sua aplicação técnica. Essa razão desconsidera a esfera teleológica, preocupada com fins que transcendem o imediato, típica da visão tradicional, e reduz tudo a meio e instrumento para satisfazer o bem-estar humano. Esse desenvolvimento da ciência e da técnica possibilitou a superação dos determinismos da natureza e da socie- 


\section{Revista Brasileira de Bioética}

dade, trazendo benefícios e independência para a humanidade, base para o desenvolvimento da autonomia.

A dinâmica cultural do individualismo, inspirador da autonomia do sujeito, e o progresso científico e tecnológico, produtor de benefícios e bem-estar para a humanidade, colocaram as bases para o surgimento de uma sociedade democrática fundamentada no Estado e no Mercado. Esta é a terceira característica da modernidade, possibilitada pela gradativa superação do sistema da dádiva que movia a sociabilidade das culturas pré-modernas. As relações sociais baseadas na confiança e no compromisso comunitário foram substituídas pelas relações formais atravessadas pela moeda (mercado) ou pelo sistema jurídico (Estado). Essa substituição tornou possível o surgimento do regime democrático. A democracia manifesta-se na tolerância a opiniões morais e religiosas, na aceitação de posicionamentos políticos diferentes, no respeito pela diversidade cultural, na defesa do estatuto das minorias. A criação dos mecanismos políticos que facilitam o exercício da democracia é uma das grandes conquistas dos tempos modernos.

Os três valores da modernidade - o individualismo impulsionado pela autonomia, o progresso científico-técnico possibilitado pela racionalidade instrumental e a sociedade democrática baseada no Mercado e no Estado - provocam maior mal-estar, causado pelas patologias socioculturais que engendram (1). A crítica de pensadores pósmodernos ao paradigma da modernidade é um sinal desse mal-estar.

O individualismo desembocou numa cultura narcisista que esvazia a própria autonomia, transformando a busca de originalidade e de autenticidade em autocomplacência. Narcisista não é o egoísta, mas aquele que perdeu sua identidade. Essa fragmentação do "eu" acontece pela falta de um princípio interior de unificação que produz um vazio de sentido, impossibilitando a autonomia da consciência. $O$ individualismo, incentivador do surgimento de um sujeito autônomo, termina produzindo um sujeito narcisista, sem identidade, à mercê das emoções do momento e, portanto, manipulável. Esse é o preço de uma compreensão não relacional da autonomia que reduz a liberdade à pura independência.

A racionalidade instrumental fragmentou a realidade para poder dominá-la. Perdeu a visão sistêmica do todo, produzindo desastres 
ambientais e sociais. O desenvolvimento da ciência e da técnica foi motivado pelos benefícios que traria para a humanidade, mas seus resultados tornaram-se também uma ameaça para ela. Esse desvirtuamento provém do paradigma de ciência que se impôs, caracterizado por uma razão fragmentada que perdeu a visão holística do mundo. O paradigma científico não consegue captar a complexidade da realidade e a interdependência dos seus elementos constitutivos, criando uma compreensão distorcida que leva à tomada de decisões e a práticas desestruturadoras e nocivas. O paradigma da ecologia surgiu como crítica e, ao mesmo tempo, alternativa para essa visão redutora do mundo; procura entender a realidade como uma rede interdependente de relações que se realimentam e retroagem. Compreende o mundo como processos auto-organizados e interconexos caracterizados pela parceria, flexibilidade, reciclagem e diversidade (2).

O anseio por democracia ficou reduzido à sua versão formal. A participação democrática limita-se, praticamente, aos momentos das eleições. A sociedade técnico-industrial exerce um despotismo sutil e invisível por meio do mercado onipresente que coisifica as relações e reduz tudo à mercadoria e ao estado tutelar que se expressa no aparato burocrático de poder. Os indivíduos acham que vivem numa democracia porque têm liberdade de consumir produtos e participar de atos de protesto, ter iniciativas livres e expressar suas opiniões. Mas, se formos analisar em maior profundidade essa sensação, ela é uma ficção de democracia, porque a sociedade está mais fragmentada, levando a uma crescente incapacidade de formular e levar a cabo objetivos comuns. A fragmentação aparece quando as pessoas se consideram mais atomizadas e menos ligadas aos seus concidadãos em projetos e lealdades comuns. Podem até sentir-se ligadas a projetos comuns, mas estes são sempre agrupamentos parciais corporativos, reunidos por interesses; não à sociedade em seu conjunto. Nessa situação de atomização e fragmentação, a democracia social torna-se uma ficção, porque ela se reduz às batalhas judiciais para defender direitos e interesses de grupos determinados, mas não os interesses de toda a sociedade.

Analisando o mal-estar em relação às três características do paradigma da modernidade - individualismo/autonomia, razão instrumen- 


\section{Revista Brasileira de Bioética}

tal/ciência-técnica e sociedade técnico-industrial/democracia - fica claro que as patologias são frutos de um esquecimento da interdependência ou interconexão dos elementos que formam a realidade, isto é, falta interpretar a natureza e a sociedade como uma rede de relações que se realimentam e se exigem mutuamente. Portanto, a tendência de atomizar e fragmentar, presente na expressão cultural do individualismo atual, no modelo dominante de ciência e técnica e na organização política da sociedade técnico-industrial, é a causa da crise e dos impasses que vivemos nos dias atuais. O paradigma ecológico é uma resposta a essa crise, porque tenta repen-sar a realidade, especificamente a natureza, como um sistema de rela-ções e dependências mútuas.

\section{O paradigma ecológico}

A crise ecológica não significa apenas o surgimento de problemas ambientais exigindo resposta, mas a emergência da necessidade de um novo paradigma de percepção do mundo e, em especial, da natureza. A solução não está em mudanças que apenas procuram obviar as conseqüências funestas do uso de uma técnica invasora dos equilíbrios homeostáticos da natureza. Impõe-se uma mutação cultural que supere a visão redutiva e alcance um enfoque mais global da natureza. Trata-se da passagem de um reducionismo científicometodológico a uma cultura sistêmica do ambiente.

De uma época de total equilíbrio e dependência do ser humano da natureza no Paleolítico, passa-se a um gradativo distanciamento iniciado com a revolução agrícola do Neolítico e chega-se ao seu auge na Revolução Industrial inaugurada no século XVIII. Do gerenciamento e domesticação dos processos naturais para defender-se da inclemência da natureza e construir um habitat humano em total harmonia com o sistema natural, passou-se ao total controle e domínio sobre os recursos naturais, pelo desenvolvimento do método científico e difusão das tecnologias, dando origem à civilização industrial povoada de luzes e de sombras.

É inegável que a industrialização melhorou significativamente a vida dos seres humanos, mas provocou, igualmente, efeitos desastrosos que agora ameaçam aqueles que ela própria procurou beneficiar. As 
conseqüências negativas não são frutos da própria ciência e técnica, mas da falta de uma cultura mais sistêmica do ambiente e de um igualitarismo com relação aos seres viventes presentes nas civilizações rurais. A civilização industrial provocou a acentuação do dualismo entre o ser humano e a natureza; a exploração dos recursos naturais a serviço das crescentes necessidades humanas; o desenvolvimento de tecnologias com impacto sobre o ambiente; o uso e a exploração de novas fontes de energia; o aumento exponencial da população; a complexificação dos sistemas sociais pelo surgimento de classes; e o desaparecimento de modos alternativos de vida pela massificação cultural. Tudo isso levou a um dissídio crescente entre a sociedade humana e o meio ambiente, a divisões e discriminações nas sociedades humanas.

Podem-se apontar vários indícios de reducionismo no modo de relacionar-se com a natureza. Os métodos de análise e de intervenção no ambiente processados pela ciência e pela técnica são inadequados, porque o conhecimento foi dividido em especialidades, faltando um saber sistêmico do conjunto. A ecologia surgiu para responder a essa necessidade. Operou-se uma fragmentação da realidade correspondente à sociedade dividida em classes e em especialidades e trabalhos e orientada à produção econômica.

A tecnologia teve desenvolvimento crescente sem atentar sobre as conseqüências sobre o ambiente. As repercussões são preocupantes e a opinião pública está apenas acordando para elas. Aconteceu igualmente uma nítida separação entre ciências naturais e humanas, entre matéria e espírito, entre ciência e fé, entre economia e ética, entre indivíduo e sociedade. Essa separação corresponde ao processo de especialização e positivação do conhecimento científico.

O aumento gradativo da população levou a uma maior procura de bens extraídos da natureza e a um incremento conseqüente da tecnologia. Assim, as potencialidades dos mecanismos naturais de adaptação e equilíbrio foram superadas e a própria adaptação cultural foi quebrada, provocando resultados desastrosos.

O modo como os humanos percebem a natureza, o ambiente e a sociedade, passou substancialmente por dois momentos. A revolução científica devido ao seu reducionismo destruiu o caráter orgânico da percepção pré-científica das sociedades tradicionais. Sob o estí- 


\section{Revista Brasileira de Bioética}

mulo da pesquisa em ecologia, a ciência dos sistemas e o enfoque estruturalista recompuseram a visão integral da realidade natural e social. Assim, estamos diante da emergência de um novo paradigma de percepção e compreensão da realidade, inspirado pela ecologia que pretende superar a visão limitada e estreita da racionalidade instrumental moderna. É necessário assumir uma racionalidade dialógica, bioempática e holística para acercar-se da realidade natural e social, para enfrentar os desafios ambientais.

O paradigma ecológico significa uma crítica radical à autonomia solipsista da modernidade e uma proposta de percepção da realidade em suas inter-relações e não como pura soma de entidades individuais. Amplia a pura perspectiva intersubjetiva dos humanos e tenta incluir também a consideração das interdependências e interligações com os seres vivos e com os ecossistemas e a biosfera. Um sistema vivente (ecossistema) não é a pura justaposição de seres vivos e fatores que possibilitam a vida, mas um complexo de interações de dinamismos vitais (3).

\section{A relação entre saúde e ambiente}

O paradigma ecológico como crítica do reducionismo científico, que fragmenta a percepção e impede uma visão sistêmica da realidade, também tem sua história de efeitos sobre a compreensão da saúde humana. A relação da saúde com o ambiente sempre foi uma preocupação humana e respondeu muito tempo pela causa das doenças na compreensão miasmática. Compreendida como um reflexo dos miasmas presentes no ambiente, a doença era explicada como essencialmente ambiental.

O progresso da biologia microbiana mudou substancialmente essa concepção. A partir de tais descobertas, a causa da doença não se restringe mais aos ares fétidos, passando a ser atribuída aos micróbios, que invadem o corpo do enfermo. O ambiente continua a ter importância, mas apenas como reservatório de hospedeiros e vetores das patologias. A causa do adoecimento deixa de ser algo vago, como o miasma, sendo identificada com o contágio por um micróbio que habita certo ambiente. Assim, surge a ecologia médica, que estuda as relações dos fatores físicos e biológicos com a doença, a inter-relação 
entre o ambiente e os vetores das patologias.

As implicações da globalização das comunicações e dos transportes e da circulação de pessoas, alimentos, animais, plantas e microorganismos são claras e resultam na alteração dos padrões clássicos da geografia da saúde e da doença. A queda das barreiras políticas e o livre trânsito de pessoas e de produtos são responsáveis, em grande parte, pelas chamadas doenças emergentes, que atualmente constituem a maior preocupação da ecologia médica. Essa é a concepção de Ávila-Pires (4) em seu clássico livro Princípios de ecologia médica.

A revolução bacteriana trouxe grandes benefícios para a humanidade, mas teve um efeito colateral negativo, o retrocesso no pensamento da medicina social, efeito que contamina até hoje a biomedicina. As novas doenças da civilização não têm origem microbiana, adquirindo o ambiente uma nova importância não apenas como reservatório, mas como um ecossistema de interdependências naturais, sociais, políticas e culturais que influenciam a saúde e a doença. Desse modo, surge a compreensão ecossistêmica da saúde, veiculada, por exemplo, pela obra Saúde e ambiente sustentável: estreitando os nós (5).

A novidade dessa concepção é que o foco da preocupação com o ambiente não é mais tanto a doença, mas a saúde; e agregam-se ao binômio saúde-ambiente os conceitos de sustentabilidade ecológica, qualidade de vida, justiça social, democracia e direitos humanos. $\mathrm{Mu}-$ da o foco porque o ambiente em seu sentido amplo é integrado na própria compreensão da saúde. Antes o ambiente era algo externo, condicionador da doença e se reduzia ao aspecto físico. É difícil atribuir a causa de qualquer doença a apenas um elemento, pois a saúde humana é influenciada não apenas por fatores específicos, mas pela interação entre eles. Essa concepção muda a compreensão sobre a presença de riscos no ambiente, necessitando uma abordagem mais complexa.

O modelo ecossistêmico une reflexões simultâneas: a de saúde e a de ambiente, tendo, como processo mediador, as análises das condições, situações e estilos de vida de grupos populacionais específicos. Isso significa conjugar saúde e ambiente entrelaçando a sustentabilidade ecológica do ambiente natural com o desenvolvimento 


\section{Revista Brasileira de Bioética}

social e não apenas econômico do entorno e com a qualidade de vida. A sustentabilidade e o desenvolvimento são a base da qualidade de vida, que, no entender de Minayo, é descrita como:

“... um processo de construção de novas subjetividades pela participação em projetos de mudanças em uma ótica de desenvolvimento sustentável e de cumplicidade com as gerações futuras. Embora existam tentativas de quantificar indicadores... a definição de qualidade de vida é eminentemente qualitativa... ao mesmo tempo, o sentimento de bem-estar, a visão de finitude dos meios para alcançá-lo e a disposição para a solidariedade, ampliar as possibilidades presentes e futuras" (6).

Dessa maneira, o enfoque ecossistêmico de saúde como qualidade de vida "é como um guarda-chuva onde estão ao abrigo nossos desejos de felicidade, nossos parâmetros de direitos humanos; nosso empenho em ampliar as fronteiras dos direitos sociais e das condições de ser saudável e de promover saúde" (7).

Outra forma de pensar a relação entre ambiente e saúde é a teoria sobre a reprodução social da saúde proposta pelo sanitarista argentino Juan Samaja $(8,9)$ que tenta pensar as relações entre a saúde e as condições de vida. Para ele, as ciências da saúde têm por objeto "os encontros e transações entre diversos espaços de valorações e regulações dos problemas que a reprodução social apresenta em todas as esferas da sociabilidade humana: biossocial, sociocultural, econômico-societal e a ecológica-política" (10).

Seguindo essa perspectiva, o objeto saúde compreende tanto as concepções e práticas sanitaristas das esferas biocomunal (reprodução biológica e ambiental), comunal-cultural (reprodução da consciência e da conduta), societária (reprodução associativa e econômica) e estatal (reprodução ecológico-política). Esse foco da saúde na reprodução social das condições de vida ultrapassa o puro espaço disciplinar da medicina, obrigando a englobar uma epidemiologia ecológica, antropológica, sociológica, jurídica, econômica e ambientalista. Para Samaja, as condições de vida determinam as situações de saúde. Portanto, as situações de saúde devem ser estudadas na perspectiva das condições de vida. Isso significa dizer que se a saúde na definição 
da OMS é o completo estado de bem-estar, então "ela é inseparável das condições de vida, e só se pode defini-la como controle sobre os processos de reprodução da vida social. Ou seja, a saúde constitui a própria ordem regular desse movimento reprodutivo" (11). Aqui saúde e ambiente estão intimamente entrelaçados, pois o ambiente identifica-se com as condições de vida que possibilitam a reprodução social da saúde.

O conceito amplo e integral de promoção da saúde, que ultrapassa a simples compreensão de prevenção, foi explicitado pela célebre Carta de Ottawa de 1996 que define a promoção da saúde como proporcionar aos povos os meios para melhorarem sua situação sanitária e exercer maior controle sobre ela. As condições e requisitos para a saúde são: a paz, a educação, a moradia, a alimentação, a renda, o ecossistema estável, a justiça social e a eqüidade. As estratégias-chave para promover a saúde incluem, segundo a Carta, o estabelecimento de políticas públicas saudáveis, a criação de ambientes favoráveis, o fortalecimento de ações comunitárias, o desenvolvimento de habilidades pessoais e a reorientação dos serviços de saúde.

Essa compreensão mais ampla e integral é um resultado das diversas conferências mundiais sobre promoção da saúde iniciadas em Ottawa. As formulações desse movimento são frutos da análise das contradições que aparecem nas cidades. As condições sanitárias dos grandes aglomerados urbanos atuais são os maiores desafios para a promoção da saúde. Por isso, surgiu a idéia das cidades saudáveis que procuram conjugar saúde e ambiente, comprometendo politicamente os municípios na criação das condições estruturais e comunitárias para um ambiente urbano saudável (12).

\section{O meio ambiente nas Declarações das Conferências das Nações Unidas sobre o Meio Ambiente e Desenvolvimento (CNUMAD)}

A crise ecológica é o resultado do drástico desajuste entre os processos cíclicos, conservadores e autocoerentes da ecosfera e os processos lineares e inovadores da tecnosfera que buscam, ao curto prazo, a maximização do benefício privado humano. Existem processos tecnológicos compatíveis com a ecosfera. É um problema de vontade humana que suporá mudanças na maneira de ver e agir com 


\section{Revista Brasileira de Bioética}

relação à natureza. Num mundo limitado, não se pode dar um crescimento ilimitado. Nossas pretensões "prometeícas" são impos-síveis e incompatíveis com a contingência da realidade.

É necessário conceber o mundo como um todo integrado por uma rede complexa de interdependências e não como simples agregado de partes: assumir o mundo como uma aldeia. Nosso compromisso é aprender a cuidar do planeta. James Lovelock (13) chega a propor uma prática científica de medicina planetária. Esse cuidado necessita mobilização e responsabilidade, pensando globalmente e atuando localmente, vendo o valor e o significado do pequeno.

As sociedades humanas desenvolveram a capacidade de intervir nesse sistema de interações e de interdependências vitais segundo objetivos e modelos próprios. Por isso, elas têm a responsabilidade de não destruir o ecossistema e a qualidade do ambiente em que vivem e agem no uso dessa capacidade. Essa responsabilidade é base para qualquer ética e direito ambiental.

Para entender o artigo 17 da Declaração Universal sobre Bioética e Direitos Humanos, que fala sobre a Proteção do Meio Ambiente, da Biosfera e da Biodiversidade, precisamos remontar a outras declarações e convenções internacionais de cunho ecológico.

Conscientes da gravidade do problema ecológico, os organismos internacionais tentaram respostas à crise ambiental. Elas têm o seu início no relatório sobre os limites do crescimento, elaborado por Dennis Meadows do Massachusetts Institute of Technology encomendado pelo chamado Clube de Roma, publicado em 1972 e reconfirmado em publicação 20 anos depois.

A primeira conferência internacional sobre meio ambiente foi convocada pelas Nações Unidas, em Estocolmo, no ano 1972, na qual foi promulgada uma declaração de proteção ao meio ambiente. Em 1982 a Assembléia Geral das Nações Unidas pediu à Comissão Mundial do Meio Ambiente e Desenvolvimento que elaborasse um programa global. Este informe, Nosso Futuro Comum, foi apresenta-do na Assembléia Geral de 1987. O documento, conhecido como Rela-tório Brundtland, sobrenome da ministra norueguesa que presidiu a Comissão, insiste em soluções políticas e jurídicas.

Em 1991 foi publicado na Suíça o documento Cuidar da Terra: estratégias para o futuro da vida, promovido por organismos internacio- 
nais e pelo Programa das Nações Unidas para o Meio Ambiente. Em 1992, aconteceu a grande Conferência das Nações Unidas para o Meio Ambiente e o Desenvolvimento, no Rio de Janeiro, aprovando vários documentos: a Declaração do Rio de Janeiro sobre o Meio Ambiente e Desenvolvimento; a Convenção sobre Mudanças Climáticas (Protocolo de Kyoto); a Declaração de Princípios sobre Florestas; a Convenção sobre Biodiversidade; e o documento mais importante a Agenda 21, depois transformada em Programa 21 ou Programa de Ação para Alcançar o Desenvolvimento Sustentável (14).

A Declaração do Rio sobre o Meio Ambiente e Desenvolvimento reafirma e amplia a declaração de Estocolmo, contendo 27 princípios ou propostas programáticas que objetivam orientar a formulação de políticas e acordos internacionais que respeitem o interesse de todos os envolvidos, o desenvolvimento global e a integridade do meio ambiente. O primeiro princípio dá o tom da Declaração: "Os seres humanos são o centro das preocupações relacionadas com o desenvolvimento sustentável. Eles têm direito a uma vida saudável e produtiva em harmonia com o meio ambiente". A perspectiva da Declaração é o desenvolvimento sustentável capaz de conjugar proteção do meio ambiente e qualidade de vida para os humanos.

O Programa 21 procura apresentar um plano de ação para alcançar os objetivos do desenvolvimento sustentável preconizado pela Declaração, apresentando 38 áreas ou programas de ação subdivididos em quatro seções: a) dimensões sociais e econômicas do desenvolvimento sustentável (7 programas); b) dimensões ambientais do desenvolvimento sustentável (14 programas); c) fortalecimento do papel dos grupos sociais implicados no desenvolvimento sustentável (9 programas); d) meios de implementação do desenvolvimento sustentável (8 programas).

É interessante notar que o maior número de ações trata das dimensões ambientais: proteção da atmosfera; gerenciamento dos recursos terrestres; combate ao desflorestamento; ecossistemas frágeis: luta contra a desertificação e seca; ecossistemas frágeis: montanhas; desenvolvimento rural e agrícola sustentáveis; conservação da biodiversidade; manejo saudável da biotecnologia; oceanos, mares e zonas costeiras; proteção da qualidade dos recursos hídricos (água doce) e do seu abastecimento; manejo ecológico das substâncias tóxicas; 
manejo ambientalmente saudável dos resíduos perigosos; manejo ambientalmente saudável dos resíduos sólidos e questões relacionadas com esgotos; manejo seguro dos resíduos radioativos.

É importante ficar atento porque essas diferentes dimensões e ações fazem parte do contexto do desenvolvimento sustentável. O perigo é que esse conceito seja esvaziado, uma vez que todos estão de acordo com ele, tornando-se algo polissêmico e gradativamente sem conteúdo. Os desafios ambientais tornaram o fator "ecologia" um elemento de rentabilidade econômica e, dessa forma, a idéia do desenvolvimento sustentável pode transformar-se numa ideologia. O desenvolvimento sustentável não pode ser reduzido a um simples acordo entre progresso econômico e proteção ambiental, pois sua efetividade depende de uma mutação cultural introduzida pelo paradigma ecológico. Desse modo, o desenvolvimento sustentável depende de uma mudança na percepção da nossa relação com a natureza e, principalmente, nos comportamentos de consumo. Existe uma contradição e um descompasso entre o desenvolvimento sustentável e a mentalidade cultural que move a sociedade de consumo.

\section{A Declaração Universal sobre Bioética e Direitos Humanos da UNESCO}

A Declaração Universal sobre Bioética e Direitos Humanos (15) foi incentivada pela UNESCO e homologada pela sua Assembléia Anual em outubro de 2005. A reunião geral que discutiu o esboço da Declaração teve a participação de 90 países e caracterizou-se, desde o início, por posições divergentes entre países ricos e pobres. Os primeiros, encabeçados pelos Estados Unidos, Alemanha, Canadá, Japão e Reino Unido, defendiam a restrição do acordo aos tópicos biomédicos e biotecnológicos da bioética. O Brasil, apoiado pelas delegações dos países latino-americanos e africanos, além da Índia e Síria, principalmente, sustentou a ampliação do texto da Declaração e conseguiu a inclusão dos campos social e ambiental. A Sociedade Brasileira de Bioética teve um papel fundamental na condução da discussão e da articulação dessa inclusão.

O artigo 17 da referida Declaração que tem como título Proteção do Meio Ambiente, da Biosfera e da Biodiversidade explicita: 
"Devida atenção deve ser dada à inter-relação de seres humanos e outras formas de vida, à importância do acesso e utilização adequada de recursos biológicos e genéticos, ao respeito pelo conhecimento tradicional e ao papel dos seres humanos na proteção do meio ambiente, da biosfera e da biodiversidade".

No texto do artigo, a proteção do meio ambiente, da biosfera e da biodiversidade está relacionada a quatro elementos aos quais é necessário estar atento: a) a inter-relação entre os humanos e os outros seres vivos; b) o uso adequado dos recursos biológicos e genéticos; c) o respeito ao conhecimento tradicional que conserva uma visão sistêmica da natureza; d) o papel dos seres humanos na proteção do ambiente.

O artigo 17 precisa ser considerado à luz de pelo menos duas referências ecológicas presentes no Preâmbulo da própria Declaração:

"Consciente da capacidade dos seres humanos de refletir sobre a sua existência e sobre o seu meio ambiente; de perceber a injustiça; de evitar o perigo; de assumir responsabilidade; de buscar cooperação e de demonstrar o sentido moral que dá expressão a princípios éticos";

e

"Conscientes de que os seres humanos são parte integral da biosfera com um papel importante na proteção um do outro e das demais formas de vida, em particular os animais".

Em ambos os casos as referências aparecem no contexto dos rápidos desenvolvimentos na ciência e na tecnologia e das conseqüentes questões éticas suscitadas pelas aplicações tecnológicas dos avanços da ciência. Por isso, o artigo $1^{\circ}$ das Disposições Gerais apresenta como escopo da Declaração tratar das "questões éticas relacionadas à medicina e às ciência da vida e às tecnologias associadas quando aplicadas aos seres humanos, levando em conta suas dimensões sociais, legais e ambientais". O artigo 2, ao tratar dos objetivos, propõe, entre 


\section{Revista Brasileira de Bioética}

outros, "promover o respeito pela dignidade humana e proteger os direitos humanos e ressaltar a importância da biodiversidade e sua conservação como uma preocupação comum da humanidade".

Existem diferenças e semelhanças entre as diferentes declarações dos Organismos das Nações Unidas sobre a proteção do meio ambiente e a própria Declaração da UNESCO, quando fala do meio ambiente. As primeiras têm como referência os desafios ecológicos que surgem do progresso econômico concebido como exploração de recursos naturais ilimitados, e sua perspectiva é o desenvolvimento sustentável. A segunda tem como referência as questões éticas que aparecem dos avanços das biotecnologias tendo como perspectiva a dignidade humana e os direitos humanos. Nos dois casos, a proteção ao meio ambiente tem como foco a saúde e a qualidade de vida do ser humano. Daí a importância de relacionar saúde e ambiente, englobando, por um lado, a sustentabilidade e, por outro, os direitos humanos. Essa relação aparece claramente na visão ecossistêmica da saúde.

A Declaração coloca-se na tradição dos documentos que se baseiam na doutrina dos direitos humanos, e parte de uma concepção de saúde que engloba condicionamentos sociais e ambientais. Por isso, a proteção do meio ambiente, da biosfera e da biodiversidade é entendida na relação entre saúde e ambiente, exigindo uma visão ecossistêmica da saúde para que se possa compreender o ambiente saudável em toda sua amplitude como um direito humano.

Alguém poderia questionar que a Declaração compreende a proteção do meio ambiente na perspectiva dos direitos humanos como uma posição antropocêntrica. Aqui é necessário introduzir a pertinente reflexão de Edgar Morin sobre como acontece a relação entre sociedade e natureza. Hoje não é mais possível separá-las, pois a ecologia natural inscreve-se na esfera antropossocial e a sociedade incide na ecosfera, criando ecossistemas mistos eco e sócio-organizados. A verdadeira realidade, polarizada pela eco-organiza-ção e pela sócioorganização, é sempre mais mista e multidimensional, tornando-se eco-bio-socioorganizada. Assim, as sociedades são entidades geoeco-bioantropológicas e os ecossistemas são antroposocioecológicos. Por isso, a ecologia geral deve englobar a dimensão antropossocial, como a antropossociologia precisa incluir a dimensão ecológica. A 
sociedade deve aprender da natureza, tornando-se mais ecológica, enquanto a natureza deve ser inserida na sociedade como algo a ser protegido como essencial para sua sobrevivência (16).

\section{Conclusão}

Na Declaração da UNESCO, a proteção do meio ambiente aparece como um direito humano, mas essa perspectiva antropocêntrica é corrigida pela sustentabilidade da biosfera e da biodiversidade. Em outras palavras, o meio ambiente só é preservado quando se tem uma visão complexa que compreende o ambiente como um sistema integral de interdependências (biosfera) e, para que este sistema esteja em equilíbrio homeostático é necessário que haja biodiversidade possibilitadora das inter-relações. Essa visão sistêmica do ambiente retroage sobre o modo de organizar a convivência social e sobre a própria visão ecossistêmica da saúde, base para compreender a saúde como um direito humano e o ambiente como componente básico do campo da saúde.

\section{Referências}

1. Taylor, BC. The ethics of authenticity. $9^{\text {th }}$ Edition. Cambridge (Ms): Harvard University Press, 2000.

2. Capra, F. A teia da vida: uma nova compreensão científica dos sistemas vivos. S. Paulo: Cultrix, 1996.

3. Junges, JR. Ética ambiental. São Leopoldo: Ed. Unisinos, 2004.

4. Ávila-Pires FD. Princípios de ecologia médica. Florianópolis: Ed. UFSC, 2000.

5. Minayo, MCS, Miranda AC. (Org.). Saúde e ambiente sustentável: estreitando os nós. Rio de Janeiro: Fiocruz, 2002

6. Minayo, MCS. Enfoque ecosistêmico de saúde e qualidade de vida. In: Minayo MCS \& Miranda, AC (orgs.) Op.cit, 2002. p.174

7. Op.cit.

8. Samaja, J. A reprodução social e a saúde. Salvador, Casa da Qualidade, 2000. pp. 95-6.

9._._._Epistemologia de la salud: reproducción social, subjetividad y transdisciplina. Buenos Aires, Lugar Editorial, 2004.

10. Op.cit. , 2000.

11. Op.cit. p. 100.

12. Andrade, LOM. \& Barreto, ICHC. Promoção da saúde e cidades/municípios saudáveis: propostas de articulação entre saúde e ambiente. In: Minayo MCS, \& Miranda, AC. (Orgs.). Op.cit., 2002.

13. Lovelock, J. Gaia. A prática científica da medicina planetar. Lisboa, Instituto Piaget, 1996.

14. Barbieri, JC. Desenvolvimento e meio ambiente. As estratégias de mudanças da 


\section{Revista Brasileira de Bioética}

Agenda 21. Petrópolis, Ed. Vozes, 1998.

15. UNESCO. Declaração Universal sobre Bioética e Direitos Humanos. Cátedra Unesco da Universidade de Brasília /Sociedade Brasileira de Bioética. Brasília, 2005.

16. Morin, E. O método 2: a vida da vida. Porto Alegre, Ed. Sulina, 2001. p. 94-95.

Recebido em 18/11/2005. Aprovado em 13/01/2006. 